\title{
Type 1 Adenylyl Cyclase Is Essential for Maintenance of Remote Contextual Fear Memory
}

\author{
Qiang Shan, Guy C.-K. Chan, and Daniel R. Storm \\ Department of Pharmacology, University of Washington, Seattle, Washington 98195
}

\begin{abstract}
Although molecular mechanisms for hippocampus-dependent memory have been extensively studied, much less is known about signaling events important for remote memory. Here we report that mice lacking type 1 adenylyl cyclase (AC1) are able to establish and retrieve remote contextual memory but unable to sustain it as long as wild-type mice. Interestingly, mice overexpressing AC1 show superior remote contextual memory even though they exhibit normal hippocampus-dependent contextual memory. These data illustrate that calcium coupling to cAMP contributes to the stability of remote memory and identifies $\mathrm{AC} 1$ as a potential drug target site to improve long-term remote memory.
\end{abstract}

Key words: calcium-sensitive adenylyl cyclase; anterior cingulate cortex; remote memory; contextual fear conditioning; memory maintenance; memory extinction

\section{Introduction}

Studies of temporally graded retrograde amnesia after hippocampal damage indicate that the hippocampus plays a time-limited role in memory consolidation (for a review see Squire and Bayley, 2007). In mice, memory for contextual fear is dependent on the hippocampus for several weeks, after which the memory becomes hippocampus independent and cortical regions become engaged for the establishment of remote memory (Frankland and Bontempi, 2005).

A number of proteins including several signal-transduction enzymes have been implicated in recently acquired, hippocampus-dependent memory through transgenic or pharmacological studies (Matynia et al., 2002). One of the pathways required for consolidation of hippocampus-dependent memory is the cAMP signal transduction system. For example, transgenic mice lacking both of the calmodulin-stimulated adenylyl cyclases, type 1 and type 8 adenylyl cyclases (AC1 and AC8), are able to acquire hippocampus-dependent memories, exhibit short-term memory, but show strong deficits in hippocampus-dependent long-term memory (Wong et al., 1999; Eckel-Mahan et al., 2008). However, molecular mechanisms underlying cortex-dependent remote memories are not as well characterized as hippocampus-dependent memory. Only a few proteins including NR1-NMDA receptors (Cui et al., 2004) and CaMKII (Frankland et al., 2001) have been shown to be essential for remote memory. Although there is extensive evidence that cAMP signaling is required for maintenance of hippocampus-dependent memory, the role of the cAMP

Received May 28, 2008; revised Sept. 9, 2008; accepted 0ct. 11, 2008

This project was supported by National Institutes of Health Grants NS20498 and MH073601. We thank members of the Storm laboratory for critical reading of this manuscript.

Correspondence should be addressed to Daniel R. Storm at the above address. E-mail: dstorm@u.washington.edu.

D0I:10.1523/JNEUROSCI.2413-08.2008

Copyright $\odot 2008$ Society for Neuroscience $\quad$ 0270-6474/08/2812864-04\$15.00/0 signal transduction system for remote memory has not been addressed.

$\mathrm{AC} 1$ is expressed in the cortex as well as hippocampus and is required for some forms of synaptic plasticity in the cortex. For example, $\mathrm{AC} 1$ knock-out mice $\left(\mathrm{AC}^{-1-}\right)$ show no LTP in the anterior cingulate cortex (ACC) (Liauw et al., 2005), a cortical region essential for remote memory retrieval and/or storage (Frankland et al., 2004; Maviel et al., 2004). Consequently, it was of interest to determine whether $\mathrm{AC} 1$ is critical for formation, retrieval or maintenance of remote memory in mice. These questions were addressed using two complementary transgenic mouse strains, $\mathrm{ACl}^{-1-}$ and $\mathrm{ACl}$ overexpression $\left(\mathrm{ACl}^{+}\right)$, both of which exhibit normal hippocampus-dependent contextual memory. In the $\mathrm{ACl}^{+}$strain, $\mathrm{AC} 1$ is overexpressed in the forebrain using the $\alpha$-CaMKII promoter (Wang et al., 2004).

\section{Materials and Methods}

Transgenic mice. $\mathrm{ACl}^{-1-}$ and $\mathrm{ACl}^{+}$were generated as previously described. Wild-type littermates were used as controls (Wu et al., 1995; Wang et al., 2004).

Adenylyl cyclase assay. Mice were killed by cervical dislocation, and the ACC was dissected and homogenized in buffer containing $50 \mathrm{~mm}$ Tris. $\mathrm{HCl}$ (pH 7.4), 2 mu $\mathrm{MgCl}_{2}, 1 \mathrm{~mm}$ EDTA, $0.5 \mathrm{~mm} \mathrm{DTT}$, and protease inhibitor mixture (Roche) with 20 strokes with the 'tight' pestle in a glass Dounce homogenizer. Homogenate was spun at $1000 \times g\left(4^{\circ} \mathrm{C}\right)$ for 5 $\mathrm{min}$, and the supernatant was centrifuged at high speed $\left(40,000 \times g, 4^{\circ} \mathrm{C}\right)$ for $1 \mathrm{~h}$ to pellet membrane fractions. Membrane pellets were resuspended and homogenized a second time in homogenization buffer. Adenylyl cyclase assays were performed with $95 \mu \mathrm{l}$ of membrane homogenate in a total volume of $250 \mu \mathrm{l}$ containing $40 \mathrm{~mm}$ Tris. $\mathrm{HCl}$ (pH 7.4), 1 mм ATP, 1.4 mм EDTA, 0.2 mм EGTA, $5.8 \mathrm{~mm} \mathrm{MgCl}_{2}, 0.2 \mathrm{~mm}$ DTT, protease inhibitor mixture, $1 \mathrm{~mm} \beta$-mercaptoethanol, $0.2 \mathrm{mM}$ IBMX, $0.1 \%$ BSA in the presence of trace amounts of $\alpha^{-32}$-ATP $\left(\sim 5.0 \times 10^{6}\right.$ $\mathrm{cpm}$ per reaction, NEN). For normalization and to monitor sample recovery, $\sim 10,000 \mathrm{cpm}$ per sample of ${ }^{3} \mathrm{H}$-cAMP (NEN) and 2 mM cAMP were also included. To measure calcium-stimulated activity, calmodulin (50 U per reaction, Sigma) and $300 \mu \mathrm{M}$ calcium (5.0 $\mu \mathrm{M}$ calculated 
a. AC1-/- Mice

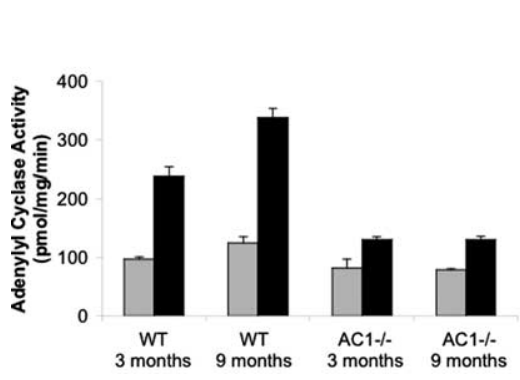

Figure 1. Calcium-stimulated adenylyl cyclase activity is altered in the anterior cingulate cortex (ACC) from AC1 ${ }^{-1-}(\boldsymbol{a})$ and $\mathrm{AC}^{+}(\boldsymbol{b})$ mice. Samples taken from mice at 3 and 9 month of age were assayed for adenylyl cyclase activity in the absence (basal) or presence of $5 \mu \mathrm{m}$ free calcium ( + Calcium) as described in Materials and Methods. WT = wild-type littermate mice. Error bars are SEM.

free calcium) were added. The Maxchelator algorithm was used to calculate free calcium concentrations (http://www.stanford.edu/ $\sim$ cpatton/maxc.html). Reactions were performed for $15 \mathrm{~min}$ at $30^{\circ} \mathrm{C}$ and stopped by the addition of $750 \mu$ l of $1.5 \%$ SDS. Samples were heated at $100^{\circ} \mathrm{C}$ for $2 \mathrm{~min}$ and then cooled and loaded onto ionic $\left(\mathrm{H}^{+}\right)$, analytical grade, 200-400 mesh, Dowex AG 50W-X4 resin columns (Bio-Rad). Finally, samples were eluted from these Dowex columns onto alumina columns (WN3 type, Sigma) with $\mathrm{ddH}_{2} \mathrm{O}$. A final elution step from the alumina columns was performed by addition of $0.1 \mathrm{M}$ imidazole. cAMP produced was determined by scintillation counting of ${ }^{32} \mathrm{P}$-cAMP and normalized to the amount of ${ }^{3} \mathrm{H}$ cAMP. A Pierce BCA assay was performed on membrane homogenates to obtain the protein concentrations, and results are expressed as pmol of cAMP per minute per milligram protein.

Contextual fear conditioning. In the "normal" training session, mice were placed in the contextual conditioning chamber (TruScan Mouse chamber, Model H10-11M-PA, Coulbourn Instruments) and allowed to explore the chamber for $2 \mathrm{~min}$. At the end of $2 \mathrm{~min}$, they received a $0.7 \mathrm{~mA}, 2$ s foot shock from the metal grid floor. In a "weak" training session, the mice were allowed to explore the chamber for only $0.5 \mathrm{~min}$ before a $0.2 \mathrm{~mA}, 1 \mathrm{~s}$ foot shock was delivered. Following the shock, the mice were kept in the chamber for an additional minute before being returned to their home cage. At various time points after training, the mice were tested by being returned to the conditioning chamber for 2 min without any shock. The percentage of time freezing was recorded and used as an index of contextual memory. Freezing behavior was defined as immobility with all 4 paws contacting the metal grid floor and was scored every 5 s during a 2 min test. Except where stated, mice were 2-3 months old at the time of the initial training.

Open field activity. Locomotor activity was measured in a $25 \mathrm{~cm} \times 25$ cm arena using TruScan 99/2.0 software (Coulbourn Instruments). Ambulatory distance was calculated by the software and is defined as the sum total of vector coordinate changes less stereotypic movement distance comprised of moves of $<2.25 \mathrm{~cm}$ followed by a return to the original coordinate.

Statistical analysis. We used Student's $t$ test for analyses. Measures are expressed as mean \pm SEM. Significance was set at $p<0.05$.

\section{Results}

\section{Calcium stimulated adenylyl cyclase activity in the anterior} cingulate cortex

To verify that $\mathrm{AC}^{-1-}$ mice exhibit a deficiency in calciumstimulated adenylyl cyclase activity in the cortex, we dissected the ACC and measured adenylyl cyclase activities in wild-type and $\mathrm{AC}^{-1-}$ mice. ACC is the most defined cortical area affecting remote contextual fear memory, although other cortical areas might also be involved (Frankland et al., 2004). To eliminate the possibility that any aging-induced AC activity change might occur, two age groups, either 3- or 9-month-old, were used. Calcium-stimulated adenylyl cyclase activity in the ACC from 3 -month-old $\mathrm{AC}^{-1-}$ mice was reduced from $238 \pm 16 \mathrm{pmol} / \mathrm{mg} / \mathrm{min}$ in wildtype mice to $130 \pm 5 \mathrm{pmol} / \mathrm{mg} / \mathrm{min}$ in the mutant mice and from $338 \pm 16$ to $131 \pm 6 \mathrm{pmol} / \mathrm{min} / \mathrm{mg}$ in 9 -month-old mice (Fig. 1a). On the other hand, calcium-stimulated adenylyl cyclase activity in the ACC of $\mathrm{ACl}^{+}$was $\sim 2$-fold greater compared with wild-type mice (Fig. 1b), consistent with previous data (Wang et al., 2004).

\section{Remote memory of AC1 knock-out and AC1 overexpressing mice \\ $\mathrm{AC} 1^{-/-}$and wild-type littermates were} trained for context and tested at various times after training to evaluate hippocampus-dependent contextual memory (tested $1 \mathrm{~d}$ after training) and remote memory (tested 3, 5, 11, and 22 weeks after training). To eliminate any contribution from extinction, individual groups of mice were tested at each time point Wild-type and $\mathrm{ACl}^{-1-}$ mice showed comparable contextual memory measured $1 \mathrm{~d}$ after training (Fig. $2 a$ ), consistent with previous reports that these mice exhibit normal hippocampusdependent contextual memory (Wong et al., 1999; Wang et al., 2004). Contextual memory of $\mathrm{ACl}^{-I-}$ mice measured 3 and 5 weeks after training was not significantly different from wild-type mice (Fig. 2a). This suggests that $\mathrm{AC} 1$ is not required for the transition from hippocampus-dependent to remote memory. There was no significant decrease in remote memory of wild-type mice measured 11 weeks after training. However, $\mathrm{AC}^{-1-}$ mice showed lower remote memory 11 weeks after training compared with wild-type mice $(28 \pm 7.1$ and $61 \pm 4.4 \%$ freezing rates, respectively, $p<0.001)$. Remote memory of wild-type mice ultimately decreased and was indistinguishable from $\mathrm{AC}^{-/-}$mice at 22 weeks. This is in contrast to much stronger training paradigms that induce persistent fear memories throughout the lifetime of rodents (e.g., Gale et al., 2004).

It is notable that the time for transfer of memories between hippocampus and neocortex sites reported by various labs differs considerably, even when the same type of memory is studied. For example, Frankland et al. (2004) showed the involvement of ACC in remote contextual memory 18-36 d after initial training. However, the shock paradigm used by Frankland et al. (2004) was different from that used in this study. Furthermore, the time for transfer may vary with training box used and the types of visual cues associated with the context.

Since by the time the mice used in these experiments were tested, their ages vary from 3 to 9 months, the loss in remote memory shown by $\mathrm{AC}^{-1-}$ mice might be due to agingdependent differences in locomotion or memory retrieval. To evaluate this possibility, 19 -week-old $\mathrm{AC}^{-1-}$ mice, comparable in age to mice tested 11 weeks after initial training, were trained for contextual fear memory and tested $24 \mathrm{~h}$ later. $\mathrm{AC}^{-1-}$ mice at this age exhibited no detectable deficiency in learning and memory retrieval (Fig. $2 b, 19$-week-old). In fact, $\mathrm{ACl}^{-l-}$ mice that were even older, with an average age of 40 weeks, continued to show normal learning and memory in contextual fear measured $24 \mathrm{~h}$ after training (Fig. $2 b, 40$-week-old). Furthermore, there was no difference in open field activity in the older $\mathrm{ACl}^{-/-}$mice. Therefore, we conclude that the memory deficiency 11 weeks 
after training was not due to aging related deficits in mobility or memory retrieval.

Based on the data above, it appears that $\mathrm{AC} 1$ is critical for remote memory maintenance rather than acquisition or retrieval since $\mathrm{AC} 1^{-/-}$mice had similar memory to wild-type mice 3 weeks after training but significantly reduced memory in 11 weeks. However, there is another possible explanation for the memory loss at 11 weeks. In principle, a strong training paradigm using an electric shock may cause a "ceiling effect" in which case the difference in memory between the two groups may be undetectable because freezing is effectively saturated. Therefore, it is possible that $\mathrm{ACl}^{-/-}$mice have a deficiency in hippocampus-dependent memory which is not detectable when measured $1 \mathrm{~d}$ after training but is revealed 11 weeks after training. To evaluate this, wild-type animals were trained for context using a weaker training paradigm ("weak" training, Materials and Methods; 1 shock, amplitude $0.2 \mathrm{~mA}$, duration $1 \mathrm{~s}$ and preexposure time $30 \mathrm{~s}$ ) while $\mathrm{AC}^{-/-}$mice were trained by the normal paradigm (1 shock, amplitude $0.7 \mathrm{~mA}$, duration $2 \mathrm{~s}$ and preexposure time $120 \mathrm{~s}$ ). Using these training paradigms, wild-type mice exhibited a slightly but statistically significantly weaker hippocampus-dependent contextual memory after $1 \mathrm{~d}$ compared with $\mathrm{AC}^{-1-}$ mice (wild type $49 \pm 5.1 \%$ versus $\mathrm{ACl}^{-/-} 63 \pm 3.5 \%, t$ test, $p<0.05$ ) (Fig. 2c). This small difference was also seen 3 weeks after training (wild type $54 \pm 6.9 \%$ versus $\mathrm{AC}^{-/-} 73 \pm$ $4.7 \%, t$ test, $p<0.05$ ). However, the persistence of remote memory measured 11 weeks after training was still lower in $\mathrm{AC} 1^{-/-}$ mice (Fig. $2 c$ ) (wild type $59 \pm 5.3 \%$ versus $\mathrm{AC} 1^{-1-} 36 \pm 5.6 \%, t$ test, $p<0.01$ ) (Fig. 2c). These data support the hypothesis that $\mathrm{AC} 1$ contributes to the persistence of remote memory.

Since AC1 is apparently critical for maintenance of remote memory, it was of interest to determine whether increasing AC1 activity prolongs remote contextual memory. To address this issue, we compared remote contextual memory of $\mathrm{ACl}^{+}$mice to wild-type littermates. $\mathrm{ACl}^{+}$and wild-type mice exhibited comparable hippocampus-dependent $1 \mathrm{~d}$ memory and cortexdependent 3-week memory (Fig. 2d). However, the persistence of remote contextual memory in $\mathrm{ACl}^{+}$mice was superior to wildtype mice (Fig. $2 d$ ). When tested 22 weeks after training, $\mathrm{ACl}^{+}$ and wild-type mice exhibited freezing levels of $51 \pm 12 \%$ and $22 \pm 5.1 \%$, respectively ( $t$ test, $p<0.05$ ). Thus, overexpression of $\mathrm{AC} 1$ results in longer-lasting remote contextual memory.

\section{Extinction of remote memory of AC1 knock-out mice}

Based on the data described above, we concluded that AC1 is critical for the persistence of remote memory. We wondered whether the $\mathrm{ACl}$ gene also affected extinction of remote memory, an active form of forgetting in which the animal learns that the context is no longer associated with a shock. There were, however, no significant differences in the rates of remote contextual memory extinction between $\mathrm{AC}^{-1-}$ and wild-type littermates 3 weeks after initial training (Fig. 3). b

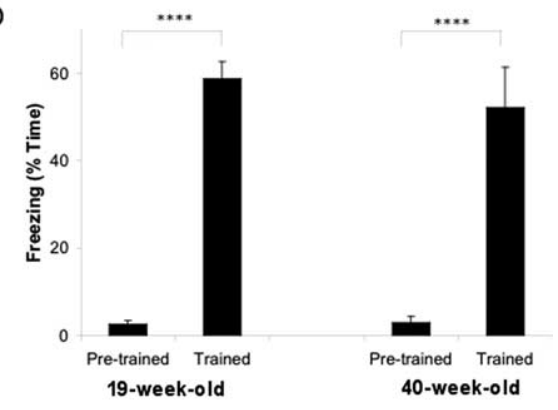

d

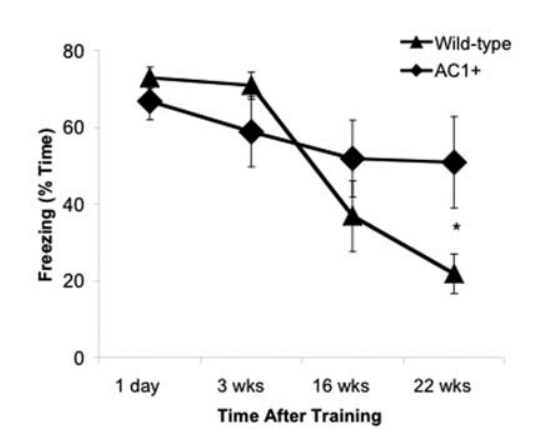

Figure 2. AC1 activity is critical for the persistence of remote contextual memory. Mice were trained for contextual memory and tested at various times after training as described in Materials and Methods. $\boldsymbol{a}, \mathrm{AC} 1^{-1-}$ and wild-type littermate mice were trained by allowing them to explore for 2 min after which they received a $0.7 \mathrm{~mA}, 2$ s foot shock from the metal grid floor. $\boldsymbol{b}, 0$ lder mA, $2 \mathrm{~s}$ foot shock) and tested for contextual memory at several times after training. $n=8$ mice in each group in all panels except the 40-week-old group with $n=6$; ${ }^{*} p<0.05,{ }^{* *} p<0.01$, ${ }^{* * *} p<0.001$, ${ }^{* * *} p<0.0004$. Error bars are SEM.
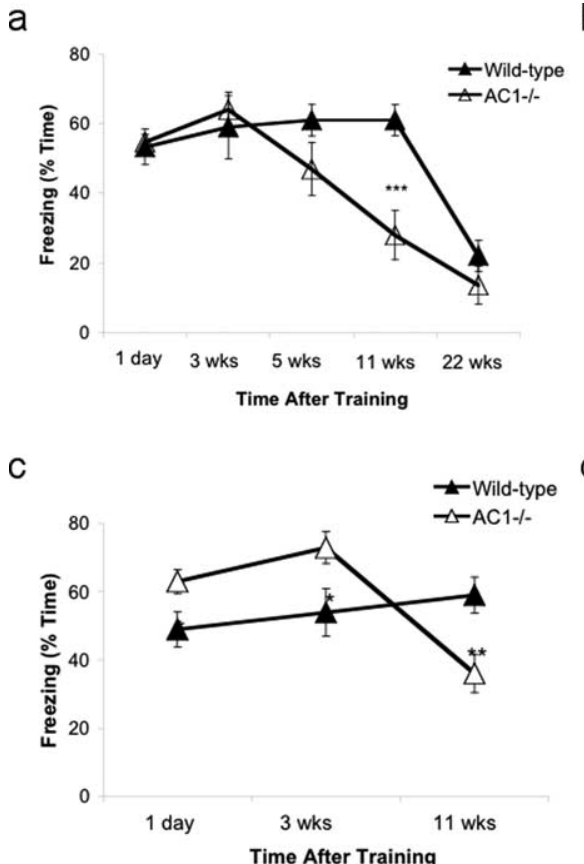
data are consistent with the observation that synaptic plasticity in the ACC is compromised in $\mathrm{AC}^{-1-}$ mice (Liauw et al., 2005).

Transgenic mouse technology has implicated several proteins in remote memory including CaM kinase II, NMDA receptors, and AC1. CaM kinase II heterozygous knock-out mice exhibit normal $1 \mathrm{~d}$ memory for contextual fear but a memory deficiency $3 \mathrm{~d}$ after training (Frankland et al., 2001). Furthermore, elevated CaM kinase II activity disrupts contextual and cued fear memory consolidation only when the transgene is activated between day 1 and day 7 rather than from day 8 through day 28 after training (Wang et al., 2003). This suggests that CaM Kinase II may play roles in the early-phase establishment of remote memory while $\mathrm{AC} 1$ is critical for late-phase maintenance of remote memory. Like AC1, NMDA receptors are seemingly important for the maintenance of remote memory. Cui et al. (2004) constructed inducible, reversible and forebrain-specific NR1 knock-out mice. These mice were trained with context when the NR1 gene was switched on. This insured the formation of normal hippocampus-dependent memory and initial remote memory. The NR1 gene was then turned off during the seventh month after training followed by the gene being switched on again until the end of the ninth month when memory was tested. The mice showed a memory deficiency implying that disruption of NMDA receptor signaling for a one-month period decreased the persistence of remote memory. Collectively these data suggest that the persistence of remote memory may depend upon the NMDAreceptor/AC1/cAMP signaling pathway.

If the only requirement to maintain remote memories is the persistence of AC1-dependent cAMP signaling, why do $\mathrm{AC1}{ }^{-1-}$ mice show reduced contextual memory $\sim 11$ weeks after training without any reduction in calcium-stimulated adenylyl cyclase activities up to 9 months of age? Even wild-type mice showed a loss of remote memory 22 weeks after initial training. Given the complexity of memory storage in the CNS, it seems likely that other signaling pathways also contribute to the maintenance of remote memories. We also cannot exclude the likely possibility that other regions of the brain, in addition to the ACC, may also be involved in the processing of remote memories.

In conclusion, although $\mathrm{ACl}$ is not required for hippocampus-dependent contextual memory, it is critical for maintaining remote contextual memory. Transgenic mice expressing increased levels of $\mathrm{ACl}$ exhibit prolonged remote memory compared with wild-type mice suggesting the interesting pos- sibility that AC1 may be a useful drug target to increase the duration of remote memory.

\section{References}

Cui Z, Wang H, Tan Y, Zaia KA, Zhang S, Tsien JZ (2004) Inducible and reversible NR1 knockout reveals crucial role of the NMDA receptor in preserving remote memories in the brain. Neuron 41:781-793.

Eckel-Mahan KL, Phan T, Han S, Wang H, Chan GC-K, Scheiner ZS, Storm DR (2008) Circadian oscillation of hippocampal MAPK activity and cAMP: implications for memory persistence. Nat Neurosci 11:1074-1082.

Frankland PW, Bontempi B (2005) The organization of recent and remote memories. Nat Rev Neurosci 6:119-130.

Frankland PW, O’Brien C, Ohno M, Kirkwood A, Silva AJ (2001) AlphaCaMKII-dependent plasticity in the cortex is required for permanent memory. Nature 411:309-313.

Frankland PW, Bontempi B, Talton LE, Kaczmarek L, Silva AJ (2004) The involvement of the anterior cingulate cortex in remote contextual fear memory. Science 304:881-883.

Gale GD, Anagnostaras SG, Godsil BP, Mitchell S, Nozawa T, Sage JR, Wiltgen B, Fanselow MS (2004) Role of the basolateral amygdala in the storage of fear memories across the adult lifetime of rats. J Neurosci 24:3810-3815.

Liauw J, Wu LJ, Zhuo M (2005) Calcium-stimulated adenylyl cyclases required for long-term potentiation in the anterior cingulate cortex. J Neurophysiol 94:878-882.

Matynia A, Kushner SA, Silva AJ (2002) Genetic approaches to molecular and cellular cognition: a focus on LTP and learning and memory. Annu Rev Genet 36:687-720.

Maviel T, Durkin TP, Menzaghi F, Bontempi B (2004) Sites of neocortical reorganization critical for remote spatial memory. Science 305:96-99.

Squire LR, Bayley PJ (2007) The neuroscience of remote memory. Curr Opin Neurobiol 17:185-196.

Wang H, Shimizu E, Tang YP, Cho M, Kyin M, Zuo W, Robinson DA, Alaimo PJ, Zhang C, Morimoto H, Zhuo M, Feng R, Shokat KM, Tsien JZ (2003) Inducible protein knockout reveals temporal requirement of CaMKII reactivation for memory consolidation in the brain. Proc Natl Acad Sci U S A 100:4287-4292.

Wang H, Ferguson GD, Pineda VV, Cundiff PE, Storm DR (2004) Overexpression of type- 1 adenylyl cyclase in mouse forebrain enhances recognition memory and LTP. Nat Neurosci 7:635-642.

Wong ST, Athos J, Figueroa XA, Pineda VV, Schaefer ML, Chavkin CC, Muglia LJ, Storm DR (1999) Calcium-stimulated adenylyl cyclase activity is critical for hippocampus-dependent long-term memory and late phase LTP. Neuron 23:787-798.

Wu ZL, Thomas SA, Villacres EC, Xia Z, Simmons ML, Chavkin C, Palmiter RD, Storm DR (1995) Altered behavior and long-term potentiation in type I adenylyl cyclase mutant mice. Proc Natl Acad Sci U S A 92:220224. 